\title{
A SIMULATION-BASED FUZZY ANALYTIC NETWORK PROCESS APPROACH IN DEVELOPING SUSTAINABLE MANUFACTURING STRATEGY
}

\author{
Lanndon Ocampo ${ }^{1}$, Eppie Clark $^{2}$ \\ 1 University of San Carlos, Department of Mechanical Engineering, Philippines \\ ${ }^{2}$ De La Salle University, Department of Industrial Engineering, Philippines
}

\author{
Corresponding author: \\ Lanndon Ocampo \\ University of San Carlos \\ Department of Mechanical Engineering \\ Cebu City, 6000 Cebu, Philippines \\ phone: (+63) 932-5101510 \\ e-mail: don_leafriser@yahoo.com
}

Received: 5 February 2015

Accepted: 20 March 2015

\begin{abstract}
This paper adopts a probabilistic fuzzy analytic network process (PROFUZANP) approach in developing a sustainable manufacturing strategy. In this hybrid method, analytic network process handles the complexity of the problem structure under consideration, fuzzy set theory is used to describe vagueness in individual decision-making and probability theory is used to handle randomness in group decision-making. This holistic methodological approach addresses complexity and uncertainty both in individual and group decision-making which is useful in modeling group decisions such as developing a sustainable manufacturing strategy. In this work, an inclusive approach of integrating traditional manufacturing strategy concepts and sustainable manufacturing principles is proposed as a unifying decision model. The proposed decision structure adopts the hierarchical structure of manufacturing strategy and explores the presence of strategic responses and stakeholders' interests as significant components of sustainability. Using PROFUZANP, the decision model identifies the content policies of sustainable manufacturing strategy. This content strategy is expected to address both competitiveness and sustainability of manufacturing firms. Results are reported in this paper along with insights and future work. The contribution of this work is the integration of manufacturing strategy and sustainability into a coherent decision framework that requires the use of PROFUZANP in dealing with complex and uncertain group decision-making problem.
\end{abstract}

KEYWORDS

simulation, analytic network process, fuzzy set theory, manufacturing strategy, sustainability.

\section{Introduction}

The foundation of sustainable manufacturing can be traced back from the early work presented in [1] which describes corporate, business and manufacturing strategies in a hierarchical top-down structure. It is claimed that manufacturing strategy supports business strategy if the sequence of decisions over a number manufacturing decision categories is consistent over an extended period of time [2]. An agreement of scholars in this field suggests that these decision categories include process technology, facilities, capacity, vertical integration, organization, manufac- turing planning and control, quality, new product introduction and human resources [1,3-6]. Each of these decision categories has a number of decisionmaking or policy areas with known available options. Policy areas that comprise each decision category were presented in [3] and [6]. With consistent decisions on these areas, manufacturing strategy forms capabilities which are preferably aligned with the intentions of the business unit and of the market [7]. These competitive priorities are cost, quality, dependability and flexibility [3-5]. This approach with several recent developments highlighted by various scholars became prominent in the literature domain 
and is widely regarded by subsequent models and approaches $[3,6,8]$.

Following the onset of concerns depicting environmental degradation, non-renewable resource consumption, waste emission, and socio-economic uprising, the role of the manufacturing industry in addressing sustainability issues becomes apparent. Sustainable manufacturing gains increasing interests in academic literature [9] which is brought about by issues relating to energy consumption, waste generation, $\mathrm{CO}_{2}$ and $\mathrm{CO}_{2}$-equivalent emissions [10, 11]. This inspires various works that create and develop approaches and tools which assess, measure, and support planning and implementation of environmentally and socially responsible manufacturing operations. Despite of all of these noble approaches famous in academic literature and in practice, a close coordination of these with the classical role of manufacturing strategy has not been clearly explored. Additionally, these areas are exclusively treated such that initiatives which promote competitive advantage have unclear links with sustainability issues and vice versa.

When manufacturing firms are confronted with issues on manufacturing strategy on one hand and sustainability issues on the other hand, decisionmaking definitely becomes complex due to the number of areas that must be taken into context which oftentimes come interrelating. Furthermore, this complexity is advanced by considering the role of stakeholders in sustainable manufacturing $[12,13]$, which was not previously explored in manufacturing strategy literature [14]. The classical manufacturing strategy model exhibits direct relations with market requirements where market creates a priority set of competitive priorities $[1,3]$. This network of influences among the business unit, manufacturing and market seems to function well when the market is solely considered. With the demands of sustainability that involve various stakeholders, an update of the classical framework becomes appropriate and necessary. In this regard, recent works explored the role of stakeholders in sustainable manufacturing $[8,12$, $13,15]$.

The specific problem that is advanced in this paper is the development of the content strategy from a comprehensive decision model that integrates sustainability and classical manufacturing strategy. This specific area is relevant both in theory and in practice as it attempts to provide guidelines and framework for manufacturing managers and policy-makers regarding decisions that must be made in specific areas of manufacturing to support both competitiveness, brought about by classical manufacturing strategy concepts, and sustainability. Early attempts of this area were performed in [16] and [17] provided methodology and conceptual approach in identifying the content of a manufacturing strategy. The departure of this work comes in two extents: (1) the development of such content strategy must be taken into context with the issues on sustainability particularly on the participation of different stakeholders, and (2) identification of such content is a multi-criteria decision-making process involving complex components where decision-making are highly uncertain.

Previous works on strategy selection and development used multi-criteria decision-making methods. A two-phased deployment process based on quality functional deployment and competitive priorities was proposed in [18]. A hybrid approach combining decision-making trial and evaluation laboratory (DEMATEL) method, analytic network process and zeroone goal programming in the selection of managements systems for phased implementation was presented in [19]. A proposed hybrid methodology in the selection of a best sustainable concept from the triple-bottom line was performed in [20]. A review on these approaches is presented elsewhere [21].

This paper elucidates a decision model that identifies policy options in manufacturing decisionmaking areas that attempts to develop sustainable manufacturing strategy using PROFUZANP. In this approach, analytic network process is used to handle decision-making complexity, fuzzy set theory is used to address vagueness of individual decision-maker's judgment and probability theory is used to handle randomness of group decision. The contribution of this work lies in developing a sustainable manufacturing strategy that addresses competitiveness and sustainability in the context of complexity and uncertainty in decision-making.

\section{Methodology}

\section{Analytic network process}

Analytic network process is the general framework of analyzing complex decisions with qualitative and quantitative components and elements $[22$, 23]. Analytic network process structures the decision problem as a network of decision components and elements with dependence relationships. The details of the approach were elaborated by previous works [24-27]. It is shown that central to the measurement of subjective or of intangible elements is the pairwise comparisons of elements with respect to an element from the same or another component [24]. These comparisons form a positive reciprocal square pairwise comparisons matrix with $\left[\mathrm{a}_{\mathrm{ij}}\right]$ elements representing the influence of $\mathrm{i}$-th element on j-th col- 
umn element. Determining the weights of these elements requires solving an eigenvalue problem where the principal eigenvector resulting from the maximum eigenvalue represents the relative weights of these elements [22]. These weights are often referred to as the local eigenvector of the pairwise comparisons matrix in the context of the analytic network process [23]:

$$
\mathrm{Aw}=\lambda_{\max }
$$

where $\mathrm{A}$ is the positive reciprocal square pairwise comparisons matrix, $\lambda_{\max }$ is the maximum eigenvalue of matrix A, and $\mathrm{w}$ is the principal eigenvector associated with $\lambda_{\max }$. The rigorous mathematical proof of this approach can be found in [22]. For consistent judgment, $\lambda_{\max }=n$, otherwise, $\lambda_{\max }>n$, where $n$ is the number of row or column elements in the square matrix A. Consistency of judgment is eventually measured using the Consistency Index (C.I.) and Consistency Ratio (C.R.). C.I. is a measure of the degree of consistency and is represented by

$$
\text { C.I. }=\left(\lambda_{\max }-n\right) /(n-1),
$$

C.R. is computed using

$$
\text { C.R. = C.I./R.I, }
$$

where R.I. is the mean consistency random index which is obtained from a large number of randomly generated pairwise comparisons matrices. The table of R.I. along with corresponding size of the pairwise comparisons matrix is presented in [22]. C.R. $\leq$ 0.10 is an acceptable degree of inconsistency [22]. Decision-makers would be asked to reconsider the pairwise comparisons in case of C.R. $>0.10$.

Local eigenvectors are plugged into the supermatrix which is defined in the framework of the analytic network process. The numerical approach of computing the global priority vector is done by normalizing columns and then raising the supermatrix to $\mathrm{p}=2 \mathrm{~N}+1$ power [28] where $\mathrm{N}$ is an arbitrary large number. This approach enables the supermatrix to converge to a limit value.

Each column of the limit supermatrix is a "unique positive column eigenvector associated with the principal eigenvalue" [29]. This principal column eigenvector assumes stable priorities of the limit supermatrix and "can be used to measure the overall relative dominance of one element over another element in a network structure" [27].

\section{Fuzzy set theory}

Fuzzy set theory is a mathematical way of handling imprecision and vagueness in decision-making, popularly known as possibility theory, which was introduced by [30]. In particular, fuzzy numbers pro- vide a way of expressing vagueness in fuzzy set theory.

A fuzzy number can be represented by a fuzzy set membership function $\mathrm{F}=\left\{\left(\mathrm{x}, \mathrm{u}_{\mathrm{F}(\mathrm{x})}\right), \mathrm{x} \in \mathbf{R}\right\}$ where $\mathrm{x}$ takes on $\mathbf{R}:-\infty<\mathrm{x}<+\infty \cdot \mathrm{u}_{\mathrm{F}(\mathrm{x})}$ is a continuous mapping on the closed interval $[0,1]$. Various forms of fuzzy numbers emerge in literature but the widely used one is the triangular fuzzy number $[29,31]$. Triangular fuzzy number (TFN) can be defined as a triple $\mathrm{TFN}=(\mathrm{l}, \mathrm{m}, \mathrm{u})$ where $\mathrm{l}, \mathrm{m}, \mathrm{u} \in \mathbf{R}$ are the lower, middle, and upper points of the TFN, respectively, along with their corresponding membership function $\mu_{\mathrm{F}(\mathrm{x})}$. An introductory discussion of fuzzy numbers and their arithmetic operations can be found in [32].

Fuzzy set theory is shown to enhance multicriteria decision-making methods in handling complex and imprecise judgments. Since most evaluators find it hard to elicit numerical judgments, more realistic evaluations use linguistic variables to represent judgment [33]. Linguistic variables take the form of phrases or sentences which are expressed in a natural language [34]. These linguistic variables can be appropriately assigned by fuzzy numbers.

\section{PROFUZANP approach}

The approach adopted in this study shares similarity with the works such as presented in [35] which transforms triangular fuzzy numbers into crisp values before raising the pairwise comparisons matrices to large powers. The formal discussion on this approach was detailed in [36]. Since any fuzzy aggregation method requires defuzzification [25], the defuzzification process used in [37] is derived from the algorithm proposed in [38]. The linguistic variables are presented in Table 1 with equivalent triangular fuzzy numbers adopted from [39].

Table 1

Linguistic variables adopted from [39].

\begin{tabular}{l|c|l|l}
\hline Linguistic scale & Code & $\begin{array}{c}\text { Triangular } \\
\text { fuzzy } \\
\text { scale }\end{array}$ & $\begin{array}{c}\text { Triangular } \\
\text { fuzzy } \\
\text { reciprocal } \\
\text { scale }\end{array}$ \\
\hline Just equal & & $(1,1,1)$ & $(1,1,1)$ \\
\hline Equal importance & $\mathrm{EQ}$ & $(1 / 2,1,3 / 2)$ & $(2 / 3,1,2)$ \\
\hline $\begin{array}{l}\text { Moderate impor- } \\
\text { tance }\end{array}$ & $\mathrm{MO}$ & $(5 / 2,3,7 / 2)$ & $(2 / 7,1 / 3,2 / 5)$ \\
\hline $\begin{array}{l}\text { Strong } \\
\text { importance }\end{array}$ & $\mathrm{ST}$ & $(9 / 2,5,11 / 2)$ & $(2 / 11,1 / 5,2 / 9)$ \\
\hline $\begin{array}{l}\text { Demonstrated } \\
\text { importance }\end{array}$ & $\mathrm{DE}$ & $(13 / 2,7,15 / 2)$ & $(2 / 15,1 / 7,2 / 13)$ \\
\hline $\begin{array}{l}\text { Extreme } \\
\text { importance }\end{array}$ & $\mathrm{EX}$ & $(17 / 2,9,9)$ & $(1 / 9,1 / 9,2 / 17)$ \\
\hline
\end{tabular}


The notations used in this paper are lifted from the notations used by works of [35]. Suppose there exists a set of $\mathrm{k}$ number of decision-makers who are performing pairwise comparisons with their judgment $\widetilde{w}_{\mathrm{ij}}^{\mathrm{k}}=\left(\mathrm{a}_{1 \mathrm{ij}}^{\mathrm{k}}, \mathrm{a}_{2 \mathrm{ij}}^{\mathrm{k}}, \mathrm{a}_{3 \mathrm{ij}}^{\mathrm{k}}\right)$, where $\widetilde{w}_{\mathrm{ij}}^{\mathrm{k}}$ represents an equivalent triangular fuzzy number on the influence of i-th element on $\mathrm{j}$-th element assessed by the k-th evaluator in the pairwise comparisons matrix and $\mathrm{a}_{1 \mathrm{ij}}^{\mathrm{k}}, \mathrm{a}_{2 \mathrm{ij}}^{\mathrm{k}}$, $\mathrm{a}_{3 \mathrm{ij}}^{\mathrm{k}}$ are the corresponding lower, middle and upper points of the fuzzy numbers, the following defuzzification algorithm is implemented.

Normalization:

$$
\begin{aligned}
& \mathrm{xa}_{1 \mathrm{ij}}^{\mathrm{k}}=\frac{\mathrm{a}_{1 \mathrm{ij}}^{\mathrm{k}}-\min \mathrm{a}_{1 \mathrm{ij}}^{\mathrm{k}}}{\Delta_{\min }^{\max }}, \\
& \mathrm{xa}_{2 \mathrm{ij}}^{\mathrm{k}}=\frac{\mathrm{a}_{2 \mathrm{ij}}^{\mathrm{k}}-\min \mathrm{a}_{1 \mathrm{ij}}^{\mathrm{k}}}{\Delta_{\min }^{\max }}, \\
& \mathrm{xa}_{3 \mathrm{ij}}^{\mathrm{k}}=\frac{\mathrm{a}_{3 \mathrm{ij}}^{\mathrm{k}}-\min \mathrm{a}_{1 \mathrm{ij}}^{\mathrm{k}}}{\Delta_{\min }^{\max }},
\end{aligned}
$$

where

$$
\Delta_{\min }^{\max }=\max a_{3 \mathrm{ij}}^{\mathrm{k}}-\min \mathrm{a}_{1 \mathrm{ij}}^{\mathrm{k}} \text {. }
$$

$\mathrm{xa}_{1 \mathrm{ij}}^{\mathrm{k}}, \mathrm{xa}_{2 \mathrm{ij}}^{\mathrm{k}}$ and $\mathrm{xa}_{3 \mathrm{ij}}^{\mathrm{k}}$ are the corresponding lower, middle and upper points of the normalized triangular fuzzy number.

Compute left-side $\left(\mathrm{xls}_{\mathrm{ij}}^{\mathrm{k}}\right)$ and right-side $\left(\operatorname{xrs}_{\mathrm{ij}}^{\mathrm{k}}\right)$ normalized values

$$
\begin{aligned}
x s_{i j}^{k} & =\frac{x a_{2 i j}^{k}}{1+x a_{2 i j}^{k}-x a_{1 i j}^{k}}, \\
x r s_{i j}^{k} & =\frac{x a_{3 i j}^{k}}{1+x a_{3 i j}^{k}-x a_{2 i j}^{k}} .
\end{aligned}
$$

Compute total normalized crisp value $\mathrm{x}_{\mathrm{ij}}^{\mathrm{k}}$

$$
x_{i j}^{k}=\frac{\operatorname{xls}_{i j}^{k}\left(1-x l s_{i j}^{k}\right)+x r s_{i j}^{k} x r s_{i j}^{k}}{1-x l s_{i j}^{k}+x r s_{i j}^{k}} .
$$

Compute crisp values $\mathrm{w}_{\mathrm{ij}}^{\mathrm{k}}$

$$
\mathrm{w}_{\mathrm{ij}}^{\mathrm{k}}=\min \mathrm{a}_{1 \mathrm{ij}}^{\mathrm{k}}+\mathrm{x}_{\mathrm{ij}}^{\mathrm{k}} \Delta_{\min }^{\max } .
$$

In aggregating judgments of individual decisionmakers however, this paper adopts a probabilistic approach defined as

$$
\widetilde{w}_{\mathrm{ij}}=\bar{w}_{\mathrm{ij}}[1 \pm(1-\alpha) \mathrm{p}],
$$

where $\widetilde{w}_{\mathrm{ij}}$ (different from $\widetilde{w}_{\mathrm{ij}}^{\mathrm{k}}$ which was defined previously) is an aggregate judgment of decision-makers from a normal distribution that represents the influence of row element on column element, $\bar{w}_{\mathrm{ij}}$ is the geometric mean of all judgments of decision-makers of $\mathrm{i}^{\text {th }}$ element on $\mathrm{j}^{\text {th }}$ element and is defined as

$$
\bar{w}_{\mathrm{ij}}=\left(\prod_{\mathrm{k}=1}^{\mathrm{K}} \mathrm{w}_{\mathrm{ij}}^{\mathrm{k}}\right)^{1 / K}
$$

$(1-\alpha)$ is the confidence level of the distribution and $\mathrm{p} \in[0,1]$ is proportion of perturbation about the geometric mean. The value of $p$ denotes a range of judgmental uncertainties that usually range from $2 \%$ to $20 \%$ as claimed in [40].

\section{Proposed Procedure}

The research procedure implemented in this paper is as follows. The decision model is adopted from [21] following a comprehensive integration of manufacturing strategy and sustainability. The details of the review together with the decision framework were presented in [21] and will not be discussed here. While the discussion in [21] focuses on developing a conceptual decision-making framework, this work elucidates a real decision-making process using the PROFUZANP approach. The model integrates classical manufacturing strategy and sustainability. Figure 1 shows the decision model developed in this work. The components namely, manufacturing decision categories, policy areas and policy options are structured in a hierarchical fashion following an elaborated discussion from literature on the details of manufacturing strategy. Policy areas and policy options have a feedback loop which means that policy areas influence policy options and vice versa. Stakeholders' interests' component directs competitive priorities that a manufacturing firm shall carry out. Due to the initial stances of manufacturing firms toward sustainability, competitive priorities impact strategic responses and these responses influence different manufacturing decision categories. These discussions were elaborated in [21] in great detail.

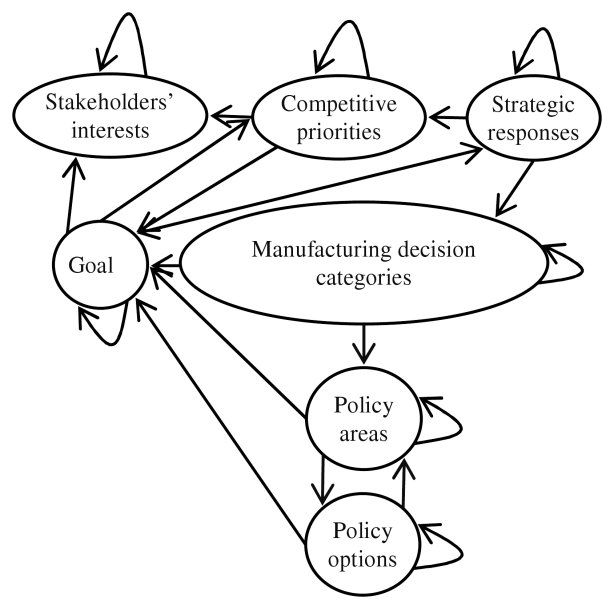

Fig. 1. Decision model (adopted from [21]).

All these components have control loops to the goal of developing a sustainable manufacturing strategy. From a practical point of view, this approach enables the goal to directly influence all components of 
the decision model. From a methodological perspective, this approach ensures that a strongly connected digraph is achieved and consequently, a primitive irreducible supermatrix is formed which is a sufficient condition for convergence to attain global priorities in the framework of the analytic network process.

Respondents were selected to provide expert judgments of the decision problem based from their expertise in the manufacturing industry. Pairwise comparisons were performed based on the relationships presented in Fig. 1 using the linguistic variables in Table 1. Using (4) through (10), corresponding crisp values of the triangular fuzzy numbers were computed.

Local priority vectors, C.I. and C.R. values of pairwise comparisons matrices were computed using (1) through (3). Using (11) and (12) by assigning random values of $\mathrm{p} \in[0,1]$ in (11) with assigned values $(0.05,0.15$ and 0.25$)$; judgments of individual decision-makers were aggregated. Local aggregated priority vectors of these matrices were obtained using (1). An initial supermatrix from the decision model was constructed and then was populated with local eigenvectors obtained in step 4 for each value of p. Normalizing columns and raising the supermatrix to large powers solves the global priority vector. This step is repeated for each value of $\mathrm{p}$, i.e. $\mathrm{p}=$ $0.05,0.15$ and 0.25 .

\section{Results}

For brevity, computations carried out in this work are not presented in this paper. All computations were performed in Microsoft Excel ${ }^{\circledR} 2010$ with VBA Excel $^{\circledR}$ Add-ins in conducting simulation runs as the result of randomly generating $\alpha$. Table 2 presents the selected policy options at different values of p. Note that $\mathrm{p}$ must not exceed 0.25 ; otherwise, uncertainty becomes uncontrollable and the decisions would not likely come from expert judgments. C.R. values likely exceed the threshold value of 0.10 at $\mathrm{p}>0.25$. Figure 2 shows the content of sustainable manufacturing strategy.

Table 2

Policy options at different values of $\mathrm{p} \in[0,1]$.

\begin{tabular}{|c|c|c|c|}
\hline \multirow{2}{*}{ Policy area } & $\mathrm{p}=0.05$ & $\mathrm{p}=0.15$ & $\mathrm{p}=0.25$ \\
\hline & Highest priority policy choice & Highest priority policy choice & Highest priority policy choice \\
\hline process choice & job shop & batch & batch \\
\hline technology & flexible manufacturing system & robotics & flexible manufacturing system \\
\hline process integration & process & process & product \\
\hline facility size & one big plant & one big plant & one big plant \\
\hline facility location & close to supplier & close to supplier & close to supplier \\
\hline facility focus & life cycle stages & life cycle stages & life cycle stages \\
\hline capacity amount & based on outputs & based on outputs & based on outputs \\
\hline capacity timing & following & following & following \\
\hline capacity type & effective & effective & forward \\
\hline direction & horizontal & horizontal & horizontal \\
\hline extent & sources of raw materials & sources of raw materials & sources of raw materials \\
\hline balance & high degree & high degree & high degree \\
\hline structure & functional & geographical & geographical \\
\hline reporting levels & first line & first line & first line \\
\hline support groups & small groups & large groups & small groups \\
\hline system design & make-to-order & make-to-stock & make-to-order \\
\hline decision support & close support & close support & close support \\
\hline systems integration & high degree & high degree & high degree \\
\hline defect prevention & high quality & high quality & high quality \\
\hline monitoring & high frequency & high frequency & high frequency \\
\hline intervention & high frequency & high frequency & high frequency \\
\hline rate of innovation & fast & fast & fast \\
\hline product design & standard & standard & standard \\
\hline industrialization & new processes & new processes & new processes \\
\hline skill level & specialized & specialized & specialized \\
\hline pay & quantity/quality of output & seniority & seniority \\
\hline security & training & promotion & promotion \\
\hline
\end{tabular}




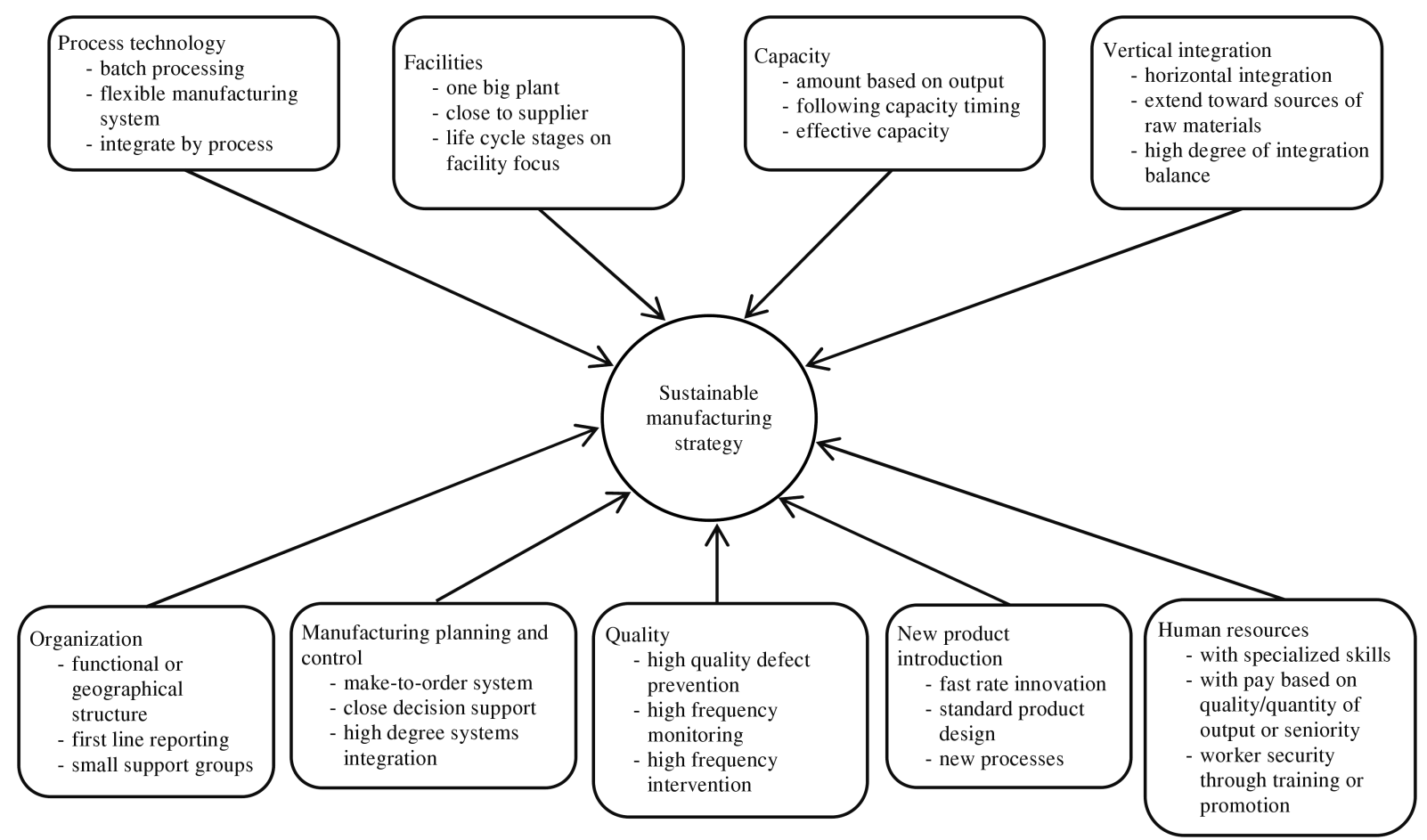

Fig. 2. Content of the Sustainable Manufacturing Strategy.

\section{Discussion and conclusion}

This work highlights a sustainable manufacturing strategy decision model that integrates classical manufacturing strategy and sustainability. Due to the complexity and uncertainty in identifying the content strategy, this paper adopts a hybrid PROFUZANP approach proposed in [30]. Fuzzy set theory handles vagueness of individual judgment while probability theory addresses randomness in aggregating experts' judgments. The proposed approach addresses uncertainty of group decision-making in the context of the analytic network process. While previous works deal with this condition to a plausible level, the hybrid method forms a group decision which is still uncertain - not a single point value provided in literature.

Using the proposed approach, the decision model provides the content of the sustainable manufacturing strategy. It shows that the content is inclined toward process-centered technology, big, product life cycle stages-focused facilities which are close to suppliers, following capacity strategy, a horizontal integration, first-line reporting with functional or geographical organizational structure, a minimal inventory-focused manufacturing planning and control, high quality prevention, monitoring and intervention policies, fast product introduction with new processes and highly skilled workers with pay based on seniority of quality/quantity of output and security focused on training or promotion. The content of the sustainable manufacturing strategy is expected to address both competitiveness and sustainability in manufacturing.

From a managerial perspective, this work extends former selection of content manufacturing strategy which focuses on narrow criterion or criteria in a limited view of stakeholders' participation. In this work, the development of the content strategy evolves from the principle of integrating competitiveness and sustainability with stakeholders' consideration in a decision framework that best describes complex reality of interrelationships between decision components. At different values of $\mathrm{p}$, the sensitivity analysis shows that minor perturbations of decisions do not change the content of the sustainable manufacturing strategy. Different combinations of stakeholders that are considered relevant in developing a sustainable strategy may lead to another set of policy options with corresponding policies. In general, the content strategy is developed by a particular set of stakeholders even if the priorities of these stakeholders change. In this case, managers should not be conscious of small policy changes of stakeholders as these will not affect the policy carried out by the firm. Unless otherwise those policy changes of stakeholders are drastic, managers must follow the policy option of each manufacturing decision area. 
This work has limitations. Results of this work must be taken into context with regard to the number of experts, their orientation, inclination and cultural differences. Furthermore, a thorough examination of the impact of orientation, inclination and cultural differences fails to be considered in the previous literature of the analytic network process. This study assumes homogeneity of expert judgments without placing more importance to experts who have more advanced knowledge and experience in manufacturing strategy and sustainability and assumes no grouping according to some defined characteristics of the group as pointed out in [24]. A future study could be done to re-examine the results when groupings and priority degree of experts are introduced.

L. Ocampo is grateful with the Ph.D. financial support of the Engineering Research and Development for Technology (ERDT) program of the Department of Science and Technology, Republic of the Philippines. An earlier version of this work was presented at the 7th IEEE International Conference Humanoid, Nanotechnology, Information Technology Communication and Control, Environment and Management (HNICEM).

\section{References}

[1] Skinner W., Manufacturing-missing link in corporate strategy, Harvard Business Review, 47,136-145, 1969.

[2] Wheelwright S.C., Reflecting corporate strategy in manufacturing decisions, Business Horizons, 21, 1, 57-66, 1978.

[3] Wheelwright S.C., Manufacturing strategy: defining the missing link, Strategic Management Journal, 5, 1, 77-91, 1984.

[4] Fine C.H., Hax A.C., Manufacturing strategy: a methodology and an illustration, Interfaces, 15, 6, 28-46, 1985.

[5] Ward P.T., Bickford D.J., Leong G.K., Configurations of manufacturing strategy, business strategy, environment and structure, Journal of Management, 22, 4, 597-626, 1996.

[6] Hallgren M., Olhager J., Quantification in manufacturing strategy: a methodology and illustration, International Journal of Production Economics, 104, 1, 113-124, 2006.

[7] Hayes R.H., Pisano G.P., Beyond world-class: The new manufacturing strategy, Harvard Business Review, 72, 1, 77-86, 1994.
[8] Johansson G., Winroth M., Introducing environmental concern in manufacturing strategies: implications for the decision criteria, Management Research Review, 33, 9, 877-899, 2010.

[9] Joung C.B., Carrell J., Sarkar P., Feng S.C., Categorization of indicators for sustainable manufacturing, Ecological Indicators, 24, 148-157, 2013.

[10] Despeisse M., Mbaye F., Ball P.D., Levers A., The emergence of sustainable manufacturing practices, Production Planning and Control, 23, 5, 354-376, 2012.

[11] Smith L., Ball P., Steps towards sustainable manufacturing through modeling material, energy and waste flows, International Journal of Production Economics, 140, 1, 227-238, 2012.

[12] Pham D.T., Thomas A.J., Fit manufacturing: a framework for sustainability, Journal of Manufacturing Technology Management, 23, 1, 103-123, 2012 .

[13] Theyel G., Hofmann K., Stakeholder relations and sustainability practices of US small and mediumsized manufacturers, Management Research Review, 35, 12, 1110-1133, 2012.

[14] Wheelwright S.C., Strategy, management, and strategic planning approaches, Interfaces, 14, 1, 1933, 1984.

[15] Griffiths A., Petrick J.A., Corporate architectures for sustainability, International Journal of Operations and Production Management, 21, 12, 1573$1585,2001$.

[16] Hallgren M., Olhager J., Quantification in manufacturing strategy: a methodology and illustration, International Journal of Production Economics, 104, 1, 113-124, 2006.

[17] Johansson G., Winroth M., Introducing environmental concern in manufacturing strategies: implications for the decision criteria, Management Research Review, 33, 9, 877-899, 2010.

[18] Barad M., Gien D., Linking improvement models to manufacturing strategies - a methodology for SMEs and other enterprises, International Journal of Production Research, 39, 12, 2675-2695, 2001.

[19] Tsai W.H., Chou W.C., Selecting management systems for sustainable development in SMEs: A novel hybrid model based on DEMATEL, ANP, and ZOGP, Expert Systems with Applications, 36, 2, 1444-1458, 2009.

[20] Vinodh S., Girubha R., PROMETHEE based sustainable concept selection, Applied Mathematical Modelling, 36, 11, 5301-5308, 2012. 
[21] Ocampo L.A., Clark E.E., A sustainable manufacturing strategy decision framework in the context of multi-criteria decision-making, Jordan Journal of Mechanical and Industrial Engineering, in press.

[22] Saaty T.L., The Analytic Hierarchy Process, New York: McGraw-Hill, 1980.

[23] Saaty T.L., Decision making with dependence and feedback: The Analytic Network Process (2nd ed.) Pittsburg: RWS Publications, 2001.

[24] Saaty T.L., The analytic hierarchy and analytic network measurement processes: applications to decisions under risk, European Journal of Pure and Applied Mathematics, 1, 1, 122-196, 2008.

[25] Saaty T.L., Relative measurement and its generalization in decision making: why pairwise comparisons are central in mathematics for the measurement of intangible factors, Journal Serie A Matemáticas, 102, 2, 251-318, 2008.

[26] Buyukyazici M., Sucu M., The analytic hierarchy and analytic network processes, Hacettepe Journal of Mathematics and Statistics, 32, 65-73, 2003.

[27] Promentilla M.A.B., Furuichi T., Ishii K., Tanikawa N., Evaluation of remedial countermeasures using the analytic network process, Waste Management, 26, 12, 1410-1421, 2006.

[28] Hsu P.F., Kuo M.H., Applying the ANP model for selecting the optimal full-service advertising agency, International Journal of Operations Research, 8, 4, 48-58, 2011.

[29] Promentilla M.A.B., Furuichi T., Ishii K., Tanikawa N., A fuzzy analytic network process for multicriteria evaluation of contaminated site remedial countermeasures, Journal of Environmental Management, 88, 3, 479-495, 2008.

[30] Zadeh L.A., Fuzzy set, Information and Control, 18, 3, 338-353, 1965.
[31] Tseng M.L., A causal and effect decision-making model of service quality expectation using grey-fuzzy DEMATEL approach, Expert Systems with Applications, 36, 4, 7738-7748, 2009.

[32] Kaufmann A., Gupta M.M., Introduction to fuzzy arithmetic: theory and applications, New York: Van Nostrand Reinhold Company, 1985.

[33] Wang R.C., Chuu S.J., Group decision-making using a fuzzy linguistic approach for evaluating the flexibility in a manufacturing system, European Journal of Operational Research, 154, 3, 563-572, 2004.

[34] Von Altrock C., Practical fuzzy-logic design, The Computer Applications Journal, 75, 1-5, 1996.

[35] Tseng M.L., Modeling sustainable production indicators with linguistic preferences, Journal of Cleaner Production, 40, 46-56, 2013.

[36] Ocampo L.A., Clark E.E., A framework for capturing uncertainty of group decision-making in the context of the AHP/ANP, Advances in Industrial Engineering and Management, 3, 3, 7-16, 2014.

[37] Tseng M.L., Wang R., Chiu A.S.F., Geng Y., Lin Y.H., Improving performance of green innovation practices under uncertainty, Journal of Cleaner Production, 40, 71-82, 2013.

[38] Opricovic S., Tzeng G.H., Defuzzification within a multi-criteria decision model, International Journal of Uncertainty, Fuzziness and Knowledge-Based Systems, 11, 5, 635-652, 2003.

[39] Tseng M.L., Lin Y.H., Chiu A.S.F., Liao J.C.H., Using FANP approach on selection of competitive priorities based on cleaner production implementation: a case study in PCB manufacturer, Taiwan, Clean Technologies and Environmental Policy, 10, 1, 17-29, 2008.

[40] Paulson D., Zahir S., Consequences of uncertainty in the analytic hierarchy process: A simulation approach, European Journal of Operational Research, 87, 1, 45-56, 1995. 